\title{
Could Alarmingly High Rates of Negative Diagnoses in Remote Rural Areas Be Minimized with Liquid-Based Cytology? Preliminary Results from the RODEO Study Team ${ }^{1}$
}

\author{
José Humberto T.G. Fregnani ${ }^{a}$ Cristovam Scapulatempo ${ }^{a}$ Raphael L. Haikel Jr ${ }^{a}$ \\ Teóclito Saccheto $^{a}$ Natália Campacci ${ }^{a}$ Edmundo C. Mauad ${ }^{a}$ \\ Adhemar Longatto-Filho ${ }^{a-d}$ \\ a Barretos Cancer Hospital, Pio XII Foundation, Barretos, and ' ${ }^{2}$ Laboratory of Medical Investigation 14, \\ Faculty of Medicine, University of São Paulo, São Paulo, Brazil; ' Life and Health Sciences Research Institute, \\ School of Health Sciences, University of Minho, Braga, and ' ICVS/3B's, PT Government Associate Laboratory, \\ Guimarães, Portugal
}

\section{Key Words}

Cytology $\cdot$ Papanicolaou test $\cdot$ SurePath $\cdot$ Cytological screening $\cdot$ Liquid-based cytology

\begin{abstract}
Objective: It was the aim of this study to compare diagnostic performances of the BD SurePath ${ }^{T M}$ liquid-based Papanicolaou test (LBC) and the conventional Papanicolaou test (CPT) in cervical samples of women from remote rural areas of Brazil. Study Design: Specimens were collected by mobile units provided by Barretos Cancer Hospital. This report evaluates the manual screening arm of the RODEO study. Of 12,048 women seen between May and December 2010, 6,001 were examined using LBC and 6,047 using CPT. $\boldsymbol{R e}$ sults: Comparative (LBC vs. CPT) outcomes were: all abnormal tests, 2.1 versus 1.0\%; ASC-US (atypical squamous cells
\end{abstract}

1 Adriana Cruvinel Carloni ${ }^{\mathrm{a}}$, Naiara Correa Nogueira-de-Souza ${ }^{\mathrm{a}}$, Maíra Stein $^{\mathrm{a}}$, Fábio de Paula Mateus ${ }^{\mathrm{a}}$, Eduardo Tadeu da Silva ${ }^{\mathrm{a}}$, Michele M. Castro Alves $^{\text {a }}$, Fábio Cardoso de Lima ${ }^{a}$, Erlaine Martins Suriano ${ }^{\mathrm{a}}$.

\section{KARGER}

Fax +4161306 1234

E-Mail karger@karger.ch

www.karger.com
C 2012 S. Karger AG, Basel

0001-5547/13/0571-0069\$38.00/0

Accessible online at:

www.karger.com/acy of unknown significance), 0.7 versus $0.1 \%$; ASC-H (atypical squamous cells with possible high-grade squamous intraepithelial lesions) and AGC (atypical glandular cells), 0.4 versus $0.3 \%$; LSIL (low-grade squamous intraepithelial lesions), 0.7 versus $0.3 \%$; HSIL (high-grade squamous intraepithelial lesions), 0.4 versus $0.2 \%$, and unsatisfactory, 0.03 versus $0.08 \%$. The $L B C$ arm detected significantly more lesions (ASC-US+) than CPT $(p<0.001)$; however, when we divided the diagnoses into two groups, ASC-H- (negative/ASC-US/ LSIL) and ASC-H+ (ASC-H/AGC/HSIL), the difference was not statistically important $(p=0.213)$. Conclusions: With inherent difficulties in patient recruitment and patient compliance with cancer screening, best test performance including human papillomavirus test capability are vitally necessary in Brazil's struggle to reduce cervical cancer.

Copyright $\odot 2012$ S. Karger AG, Basel
Correspondence to: Dr. Adhemar Longatto-Filho

Laboratory of Medical Investigation 14

Faculty of Medicine, University of São Paulo

1246-903 São Paulo (Brazil)

E-Mail longatto16@hotmail.com 


\section{Introduction}

Cervical cancer prevention can be likened to a threelegged stool, with the seat representing cancer reduction and the legs comprising patient access [1], accurate and reliable testing [2], and a responsive medical infrastructure $[1,3]$. Brazil's geography and the socioeconomic depression of rural Brazil challenge public health authorities charged with reducing cervical cancer [2].

Barretos Cancer Hospital remains among Brazil's most active cancer hospitals, and in answering geographic challenges, the hospital has, for decades, used mobile units (MUs) to enable the collection and preparation of patient samples, colposcopy examinations and minor surgical procedures. Under the auspices of the hospital and with the cooperation of local government authorities, physicians, nurses and ancillary service professionals work with community agents to recruit and educate target populations for cancer prevention programs [3].

Due in part to its historical role in reducing cervical cancer prevalence in the late 1950s and 1960s, the conventional Papanicolaou (Pap) test (CPT) is Brazil's benchmark cervical cancer screening test. Unfortunately, incidence and mortality of cervical cancer remain high among Brazil's rural poor, and failure to remedy this situation lies in part with collecting, preparing and fixing cervical cytology samples, whose simplicity has been overstated and whose complexity has been underappreciated $[4,5]$. The BD SurePath ${ }^{\mathrm{TM}}$ liquid-based Pap test (LBC) standardizes fixation, slide preparation and slide staining. It is a technical advancement that also opens the door for computer-assisted slide analysis, human papillomavirus detection and other molecular testing [6]. The RODEO study will evaluate the impact of MU-based LBC on cervical disease detection, and this publication offers preliminary results of the implementation of LBC.

\section{Material and Methods}

\section{Study Design}

RODEO is a prospective multi-center study evaluating 30,000 women from Barretos Cancer Hospital (Barretos, Brazil) as well as from Leonor Mendes de Barros Hospital and Hospital das Clínicas of São Paulo State University (São Paulo, Brazil). It is intended to offer best practices for the control and prevention of cervical cancer among Brazilian women, especially among those from impoverished, generally rural, high-risk areas including regions of the Amazon River basin. The current report offers preliminary data of conventional and direct-to-vial collections obtained by the MUs of Barretos Cancer Hospital (fig. 1).
Eligibility Criteria and Consent

Women were considered eligible for the study if their clinical assessment allowed for cervical cytological examination. Participants gave informed consent to participate in the study protocol that was approved by the ethics committee of Barretos Cancer Hospital (No. 244/2009).

\section{Group Allocation}

The first examination of the day was random sampling; thereafter, sampling alternated in accordance with the time of day (e.g. morning or afternoon). When the MUs remained in an area for several days, LBC and CPT samplings were performed on alternate days.

\section{Sample Collection and Preparation}

The CPT sample was collected with a wooden Ayre spatula and a Rovers ${ }^{\circledR}$ Cervex-Brush ${ }^{\circledR}$ Combi, smeared on a glass slide and spray fixed. The LBC sample was collected with a Rovers Cervex-Brush Combi, transferred into an LBC fixative and sent to the laboratory, where slides were prepared according to the manufacturer's instructions.

\section{Cytological Interpretation}

The cytology classification system of Brazil reflects the 2001 Bethesda System [7].

\section{Statistical Analysis}

Data were exported to SPSS for Windows ${ }^{\circledR}$ version 17.0 (SPSS Inc., Chicago, Ill., USA). The t test was used to compare women's ages. Differences between the two sampling systems were compared using the $\chi^{2}$ and Fisher's exact test, with significance levels set at $5 \%$. Confidence intervals for proportions were calculated.

\section{Results}

The study set comprised 12,048 consecutively examined women. The study interval was from May to December 2010. 6,001 (49\%) individuals, with a mean age of 46.5 \pm 12.5 years, were examined using LBC, and 6,047 (51\%) individuals, with a mean age of $46.1 \pm 13.3$ years, were examined using CPT.

The geographic distribution of source material from seven Brazilian states was as follows: Acre (0.24\%), Goiás (1.68\%), Minas Gerais (2.71\%), Mato Grosso do Sul (3.11\%), Mato Grosso (27.9\%), Rondônia (8.31\%) and São Paulo (55.97\%) (fig. 2).

Comparative (LBC vs. CPT) outcomes were: all normals, 97.9 versus $99.0 \%$; all abnormals, 2.1 versus $1.0 \%$; unsatisfactory tests, 0.03 versus $0.08 \%$. Data are further detailed in table 1 . Table 2 presents the frequency of negative + ASC-US (atypical squamous cells of unknown significance) + LSIL (low-grade squamous intraepithelial lesions) and ASC-H (atypical squamous cells with possible 
Fig. 1. Study design flow charts representing the comparison of CPT versus LBC. In this present study, only preliminary results from the manual arm were analyzed. The computer-assisted analyses of Focal Point Guided Station (FPGS) were not reported.

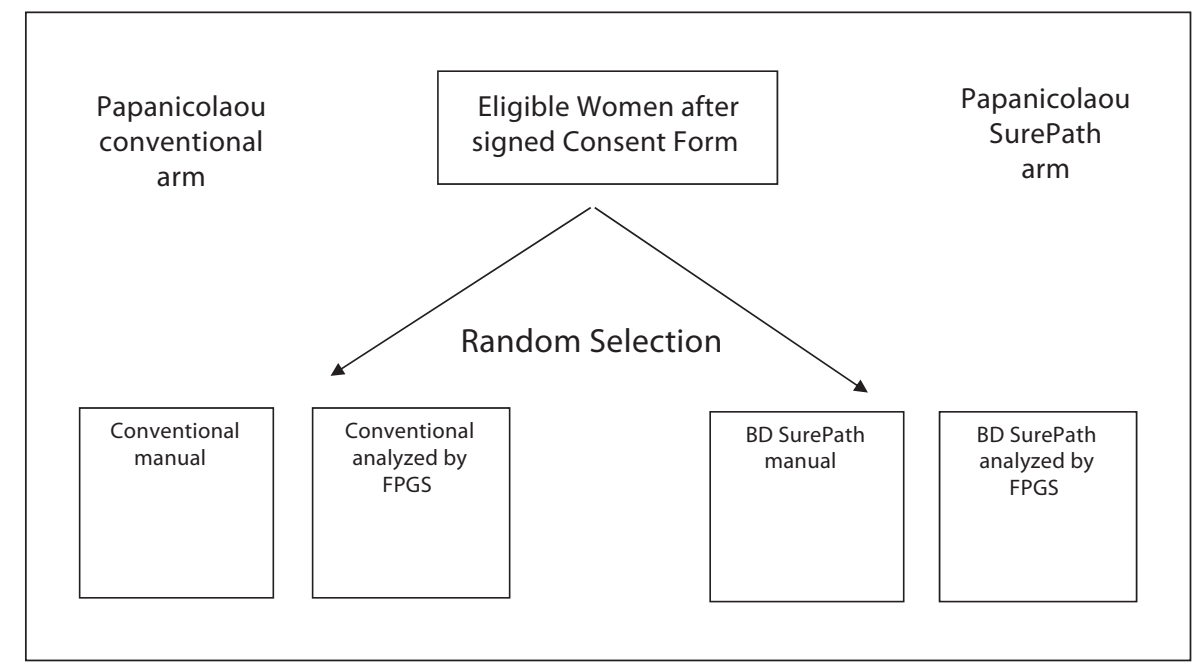

high-grade squamous intraepithelial lesions) + AGC (atypical glandular cells) + HSIL (high-grade squamous intraepithelial lesions), according to the type of cytology preparation: 99.2 and $0.8 \%$ for LBC and 99.4 and $0.6 \%$ for $\mathrm{CPT}$, respectively. Table 3 shows the distribution of $\mathrm{LBC}$ cytology results according to the study period. There was a clear reduction in ASC-US as the study progressed. A similar pattern was observed for ASC-H.

\section{Discussion}

In Brazil, the cervical cancer screening and control program has been implemented at the national level more than 30 years ago. Various authors have observed that for the country as a whole, mortality from cervical cancer has remained virtually stable. Cervical cancer is ranked second among the leading causes of death from cancer in Brazil's female population, with a downward trend for the country as a whole, a decline in the State capitals, but a stable trend among its interior municipalities [8].

Methodological advances have proven essential to outcome improvement in gynecological cytology and cancer prevention. The CPT performance falls short of that of LBC. The main reasons for the improved performance of LBC are the control of fixation, cell transfer (with the randomized distribution of abnormal cells) and presentation, affording uniform and consistently stained monolayers [4].

In the hands of seasoned health care providers, as exemplified by the members of the MU teams, LBC appeared to outperform CPT. Larger sample sizes (compris-

Cytology in Remote and Rural Areas

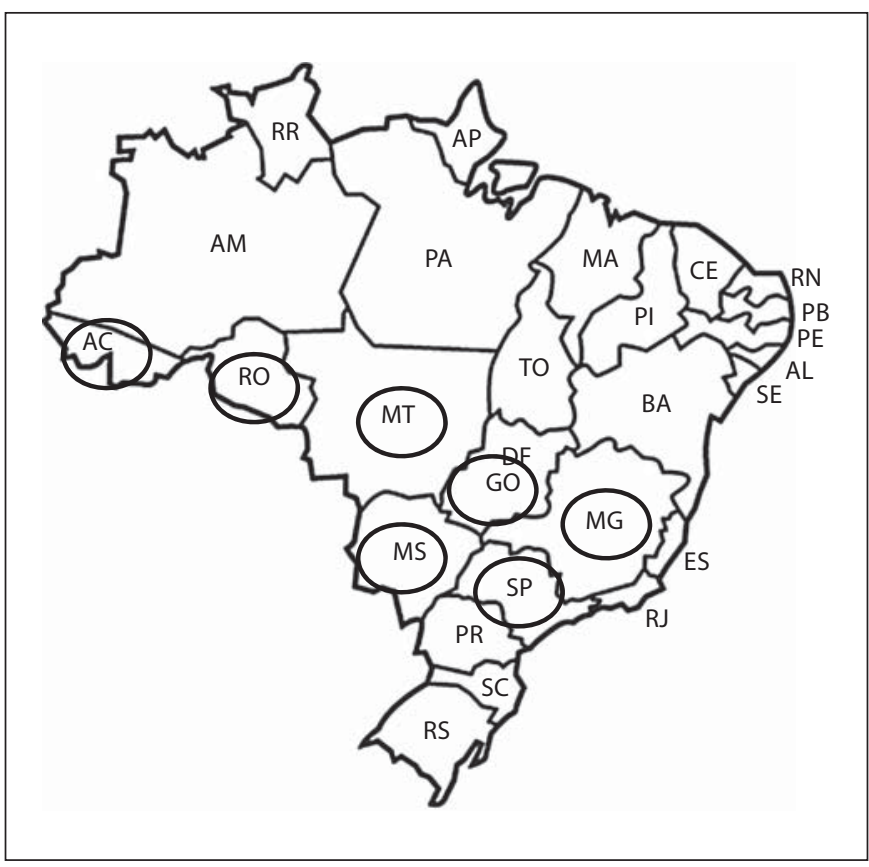

Fig. 2. The route of MUs in seven Brazilian States representing more than $6,000 \mathrm{~km}$ of traveling.

ing around 27,500-34,500 patients in each arm) would be needed to demonstrate statistically improved detection of abnormal tests (ASC-H and higher) and a meaningful reduction in unsatisfactory samples. Likewise, although HSIL appears twice as often in the LBC group, a statistically valid separation requires larger sample sizes. 
Table 1. Overall distribution of cytological examination according to the type of cytology preparation and the 2001 Bethesda System classification

\begin{tabular}{|c|c|c|c|c|c|c|}
\hline \multirow{3}{*}{$\begin{array}{l}\text { Pap } \\
\text { test result }\end{array}$} & \multicolumn{6}{|c|}{ Type of cytology preparation } \\
\hline & \multicolumn{3}{|l|}{ LBC } & \multicolumn{3}{|l|}{$\mathrm{CPT}$} \\
\hline & $\mathrm{n}$ & $\%$ & $95 \% \mathrm{CI}$ & $\mathrm{n}$ & $\%$ & $95 \% \mathrm{CI}$ \\
\hline Negative & 5,872 & 97.9 & $95.4-100$ & 5,981 & 99.0 & $96.5-100$ \\
\hline ASC-US & 39 & 0.7 & $0.5-0.9$ & 6 & 0.1 & $0.04-0.2$ \\
\hline HSIL & 22 & 0.4 & $0.2-0.6$ & 14 & 0.2 & $0.1-0.4$ \\
\hline AGC & 1 & 0.02 & $0.004-0.09$ & 1 & 0.02 & $0.004-0.09$ \\
\hline Total & 5,999 & 100.0 & - & 6,042 & 100.0 & - \\
\hline
\end{tabular}

Unsatisfactory cases were excluded. 95\% CI = 95\% Confidence interval for proportions. $\chi^{2}$ test, $\mathrm{p}<0.001$.

Table 2. Distribution of Pap test results according to the type of cytology preparation

\begin{tabular}{lcc}
\hline Pap test result & \multicolumn{2}{l}{ Type of cytology } \\
\cline { 2 - 3 } & LBC & CPT \\
\hline ASC-H-(negative/ASC-US/LSIL) & $5,952(99.2)$ & $6,006(99.4)$ \\
ASC-H+(ASC-H/AGC/HSIL) & $47(0.8)$ & $36(0.6)$ \\
\hline Total & $5,999(100.0)$ & $6,042(100.0)$ \\
\hline
\end{tabular}

Figures in parentheses are percentages. Prevalence rate $=1.3, p=0.213$ ( $\chi^{2}$ test).

Table 3. Distribution of cytology results according to the study period

\begin{tabular}{|c|c|c|c|c|c|c|c|}
\hline $\begin{array}{l}\text { Cytology } \\
\text { result (LBC) }\end{array}$ & $\leq 1,000$ & $1,001-2,000$ & $2,001-3,000$ & $3,001-4,000$ & $4,001-5,000$ & $>5,000$ & Total \\
\hline ASC-US & $15(38.5)$ & $8(20.5)$ & $4(10.3)$ & $5(12.8)$ & $4(10.3)$ & $3(7.7)$ & $39(100.0)$ \\
\hline ASC-H & $6(25.0)$ & $3(12.5)$ & $3(12.5)$ & $8(33.3)$ & $3(12.5)$ & $1(4.2)$ & $24(100.0)$ \\
\hline LSIL & $6(14.6)$ & $3(7.3)$ & $9(22.0)$ & $8(19.5)$ & $11(26.8)$ & $4(9.8)$ & $41(100.0)$ \\
\hline
\end{tabular}

Figures in parentheses are percentages.

ASC-US was reported more frequently in the LBC arm of the study (0.7 vs. $0.1 \%$ ); however, with increasing experience, there was a clear decrease in ASC-US reporting, and this was interpreted as a learning curve effect. If ASC-US and ASC-H are not taken into consideration, the LSIL + HSIL proportions for $\mathrm{LBC}$ remain twice that of CPT (1.1 vs.
0.5\%). Among high-risk Brazilian women, LBC has been shown to outperform CPT [9]; however, its superiority has not been borne out among low-risk women [9-12]. Nonetheless, in the setting of a community whose population numbers in the millions, small proportional differences equate to significant differences among actual patients. 
Unfortunately, this study also exposes a dark side to cytology screening in Brazil. For the sake of comparison, mortality from cervical cancer in Victoria (Australia) declined gradually over time, and since 2002 , it has been around 1.0 per 100,000 women (1.4 per 100,000 women for Australia as a whole; 2008 International Cancer Screening Network data of the US National Cancer Institute), which is among the lowest cervical cancer death rates in the world. Over the same interval, Brazil's mortality rate was about 10.9 per 100,000 women - more than 10 -fold greater than that of Victoria. However, one must take into consideration that there are differences in incidence and mortality depending on how the data are collected. There is urgent need to improve the quality of population-based cancer registries in low-income countries [13].

One of the most disturbing aspects of this preliminary report, and one that should affect Brazil's approach to cervical cancer screening, is that preliminary data show an alarmingly high 'negative' rate, regardless of the mode of cytological screening (97.9\% for LBC and $99.0 \%$ for CPT). Of unequivocal abnormal diagnoses, the reported data show a HSIL + LSIL rate of between 1.1 and $0.5 \%$ (based on both LBC and CPT diagnoses). These outcomes, compared to the 2010 results of the Victorian Cervical Cytology Registry, showed that the proportion of Pap tests with identical squamous cell abnormalities was 6.4\% - a rate between 5- and 12-fold higher for Australian as compared to Brazilian women at a time when cervical cancer was 10-fold lower for Australian versus Brazilian women [14]. The reasons for the low rates of cytological alterations detected at screening are certainly ample and complex, but we can hypothesize that differences in cervical lesion prevalence (very low) in rural areas could influence the Pap performance. Furthermore, the low sensitivity of the Pap test is well recognized even in optimal scenarios. On the other hand, the training of all professionals involved in screening programs based on cytology could be revised, the theoretical issues amplified and periodical re-training programs considered to increase the quality of sample collection and preparation, as well as the slide analyses. Moreover, formal examination of theory and practice could be implemented with rigid proficiency exams. The workload should be officially estipulate to 40-50 slides per day. Currently, there are only recommendations for best practices, and the cytotechnicians are free to read more than that for $8 \mathrm{~h}$. The skills and salaries of cytotechnicians could also be raised. However, all these options will certainly increase the very low prices of Pap tests in Brazil. We are now aiming for a new concept of cytological screening in Barretos Cancer Hospital, and the introduction of LBC is a first step to improve quality. Investments in the education of cytotechnicians are also being implemented by integrating these professionals in graduation courses. The augmented frequency of HSIL in the LBC arm certainly endorses the next steps that comprise automation for reading slides (Focalpoint BD system is under evaluation) and improvements in the internal quality control system for cytological diagnoses that is currently based on the revision of $10 \%$ of negative cases and the revision of all ASC-US+ cases.

Given the current astronomical discrepancies on cytological alteration frequencies, one wonders whether Brazil should 'read the writing on the proverbial wall' and altogether abandon gynecological cytology screening in favor of high-risk human papillomavirus testing, which has shown great promise among Latin American and Eastern European populations as a stand-alone detection method for cervical cancer and its immediate precursors, cervical intraepithelial neoplasia 2 and 3 [15].

\section{Acknowledgements}

The authors are indebted to Dr. John Maksem for reading and commenting on the manuscript and to the nurses of Mobile Units for their exceptional work in the poor communities. The study was partially supported by BD that donated the SurePath vials and Papanicolaou staining reagents.

\section{Disclosure Statement}

The authors declare that there are no individual competing interests.

References

1 Mauad EC, Nicolau SM, Moreira LF, et al: Adherence to cervical and breast cancer programs is crucial to improving screening performance. Rural Remote Health 2009;9: 1241.

-2 Mauad EC, Gomes UA, Nogueira JL, et al: Prevention of cervical cancer in a poor population in Brazil. Fam Pract 2002;19:189-192.

- 3 Mauad EC, Nicolau SM, Gomes UA, et al: Can mobile units improve the strategies for cervical cancer prevention? Diagn Cytopathol 2010;38:727-730

4 Longatto-Filho A, Schmitt FC: Gynecological cytology: too old to be a pop star but too young to die. Diagn Cytopathol 2007;35: 672-673. 
5 Gamarra CJ, Valente JG, Silva GA: Correction for reported cervical cancer mortality data in Brazil, 1996-2005. Rev Saude Publica 2010;44:629-638.

-6 Longatto-Filho A, Schmitt FC: Cytology education in the 21st century: living in the past or crossing the Rubicon? Acta Cytol 2010;54: 654-656.

7 Solomon D, Davey D, Kurman R, Moriarty A, O'Connor D, Prey M, Raab S, Sherman M, Wilbur D, Wright T Jr, Young N, Forum Group Members, Bethesda 2001 Workshop: The 2001 Bethesda System: terminology for reporting results of cervical cytology. JAMA 2002;287:2114-2119.

$>8$ Azevedo e Silva G, Girianelli VR, Gamarra CJ, Bustamante-Teixeira MT: Cervical cancer mortality trends in Brazil, 1981-2006. Cad Saude Publica 2010;26:2399-2407. $\checkmark 9$ Longatto-Filho A, Pereira SM, Di Loreto C, et al: DCS liquid-based system is more effective than conventional smears to diagnosis of cervical lesions: study in high-risk population with biopsy-based confirmation. Gynecol Oncol 2005;97:497-500.

10 Davey E, Barratt A, Irwig L, et al: Effect of study design and quality on unsatisfactory rates, cytology classifications, and accuracy in liquid-based versus conventional cervical cytology: a systematic review. Lancet 2006; 367:122-132.

11 Arbyn M, Bergeron C, Klinkhamer P, et al: Liquid compared with conventional cervical cytology: a systematic review and meta-analysis. Obstet Gynecol 2008;111:167-177.

12 Longatto-Filho A, Maeda MY, Erzen M, et al: Conventional Pap smear and liquid-based cytology as screening tools in low-resource settings in Latin America: experience of the Latin American screening study. Acta Cytol 2005;49:500-506.
13 Forouzanfar $\mathrm{MH}$, Foreman KJ, Delossantos AM, Lozano R, Lopez AD, Murray CJ, Naghavi M: Breast and cervical cancer in 187 countries between 1980 and 2010:a systematic analysis. Lancet 2011;378:1461-1484.

14 Brotherton JM, Fridman M, May CL, Chappell G, Saville AM, Gertig DM: Early effect of the HPV vaccination programme on cervical abnormalities in Victoria, Australia: an ecological study. Lancet 2011;377:20852092.

15 Sarian LO, Derchain S, Shabalova I, Tatti S, Naud P, Longatto-Filho A, Syrjänen S, Syrjänen K, Members of the Latin American Screening Study (LAMS), New Independent States of the Former Soviet Union (NIS) groups: Optional screening strategies for cervical cancer using stand alone tests and their combinations among low- and medium-income populations in Latin America and Eastern Europe. J Med Screen 2010;17: 195-203. 


\section{Erratum}

In the article by Fregnani et al., entitled 'Could alarmingly high rates of negative diagnoses in remote rural areas be minimized with liquid-based cytology? Preliminary results from the RODEO Study Team' [Acta Cytologica 2013;57:69-74, DOI: 10.1159/000343046], the RODEO Study Team needs to be included in the list of authors so that it reads:

José Humberto T.G. Fregnani ${ }^{\mathrm{a}}$ Cristovam Scapulatempo ${ }^{\mathrm{a}}$ Raphael L. Haikel Jr ${ }^{\mathrm{a}}$ Teóclito Saccheto ${ }^{\mathrm{a}}$ Natália Campaccia ${ }^{\mathrm{a}}$ Edmundo C. Mauad ${ }^{\mathrm{a}}$

Adhemar Longatto-Filho ${ }^{\text {a-d }}$ Rodeo Study Team ${ }^{1}$

aBarretos Cancer Hospital, Pio XII Foundation, Barretos, and baboratory of Medical Investigation 14, Faculty of Medicine, University of São Paulo, São Paulo, Brazil; ' Life and Health Sciences Research Institute, School of Health Sciences, University of Minho, Braga, and 'ICVS/3B's, PT Government Associate Laboratory, Guimarães, Portugal

1 Adriana Cruvinel Carloni, Naiara Correa Nogueira-de-Souza, Maíra Stein, Fábio de Paula Mateus, Eduardo Tadeu da Silva, Michele M. Castro Alves, Fábio Cardoso de Lima, Erlaine Martins Suriano (all with affiliation ${ }^{\text {a). }}$. 